\title{
Wildfires in Botswana and Their Frequency of Occurrence
}

\author{
Kago Ernest Maabong1, Kgakgamatso Mphale² \\ ${ }^{1}$ Department of Physical \& Chemical Sciences, Botswana University of Agriculture and Natural Resources, Gaborone, Botswana \\ ${ }^{2}$ Department of Physics, University of Botswana, Gaborone, Botswana \\ Email: kmaabong@buan.ac.bw
}

How to cite this paper: Maabong, K.E. and Mphale, K. (2021) Wildfires in Botswana and Their Frequency of Occurrence. Atmospheric and Climate Sciences, 11, 689-696. https://doi.org/10.4236/acs.2021.114040

Received: April 27, 2021

Accepted: September 10, 2021

Published: September 13, 2021

Copyright (c) 2021 by author(s) and Scientific Research Publishing Inc. This work is licensed under the Creative Commons Attribution International License (CC BY 4.0).

http://creativecommons.org/licenses/by/4.0/ (c) (i) Open Access

\begin{abstract}
Fires play an essential part in the maintenance of the environment, but amplified fire activity often leads to adverse effects in the environment such as destruction of property and loss of life. Botswana has experienced wildfires that are caused by humans intentionally and unintentionally. Some of these wildfires grow into mega fires such as the 2008 wildfires. Data of wildfires reported in Botswana from the Department of Forestry and Range Resources and the frequency of occurrence was studied and analyzed. It shows the period of 2006-2017, Ghanzi and Ngamiland districts were mostly affected by wildfires. These districts have protected land such as the wildlife parks which may lead to the outbreak of natural wildfires that burns unnoticed due to minimal movements of people. The wildfires reported in each district show an increase over the years and this may affect the smooth running of operations.
\end{abstract}

\section{Keywords}

Wildfires, Botswana, Fire Frequency, Area Burned

\section{Introduction}

Botswana is one of the sub-Saharan countries that is affected by large wildfires. These wildfires usually start between April and June, but they are not as intense as fires experienced in the late season from August to October [1]. This is because, in the late season, fires occur when the vegetation is dry and are uncontrollable due to heat and strong winds. Wildfires are either natural or unnatural. Natural wildfires are those caused by lightning usually during the rainy season and unnatural wildfires are those caused by human intervention. Botswana wildfires are usually caused by humans, intentionally or unintentionally. According to the Department of Forestry and Range Resources (DFRR), some wildfires are 
started through the use of "fire as a tool", and that include agricultural management, honey collection, grazing and harvesting management. Some are accidental and that includes recklessness when cooking, disposing of the cigarette without making sure that it's out among others. Fire management records show that most of the wildfires are reported to have started near settlements which support the fact that wildfires are human-induced. Wildfires reported well in time are usually controllable and can be extinguished before they turn into mega fires. Mega fires are usually defined by their impacts and according to (William et al., 2011 [2]) these are the most damaging, costly and destructive. Botswana recorded mega fires in the year 2008 where 3.6 million hectares of Ghanzi district was burned and most of which was the Central Kalahari Game Reserve (CKGR). This affected the country negatively as lots of funds were used in fighting these fires. Animal and plants lives were also affected. Records by Statistics Botswana show that the Ngamiland region usually records a greater number of fire occurrences followed by the Central District. By US standards, most fires recorded in the country are enormous. The largest total area affected by fires was recorded in 2011 (15,439,034 hectares). Districts which were affected mostly were Ghanzi, Ngamiland, and Kgalagadi respectively [3]. Because of the district sizes, sometimes fires may start and be extinguished by the rainy season in these areas without being spotted.

\section{The El Niño-Southern Oscillation (ENSO) and Wildfires in Botswana}

ENSO is a good predictor of seasonal forecast in Southern Africa [4]. El Niño events favor drought in this region. For instance, in 1992-1993, 2002-2003 and 2015-2016, El Niño events were associated with severe drought experienced in the region. The UN Food and Agriculture Organization (FAO) reported that in 2015-2016 El Niño episode in Southern Africa was one of the strongest in the last 50 years. It is also highlighted in the Asian regional report that in the years 1982-1983 were greatly influenced by ENSO. This led to an extended drought in Western Africa leading to intense fire occurrences. Mega fires in Botswana in 2008 and 2010 were also linked to exceptionally high rainfall experienced due to the effect of the La Niña episode and fuels from low burning of the previous years [5]. Byakatonda, J. et al. investigated the relationship between Botswana's climate and ENSO, which they found a close relationship. They associated drought years with El Niño times due to high temperatures and less rainfall. Although they concluded that there is a peak in the relationship between December and January (rainy days), this is the time when vegetation and grass grow to fuel flames during the dry season [6]. Urrutia-Jalabert, et al. (2018) evaluated the relationship between fire occurrence (number and burned area) and climate change (maximum temperatures and rainfall) in Chile. They observed a strong positive correlation between maximum temperatures and fire occurrences. From this, the authors drew conclusions that fires in Chile have a significant relation with ENSO [7]. 


\section{Annual Fire Trends in Botswana}

Statistics for annual fire reported and size of area burnt were collected from Department of Fire and Range Resources. The data is for the years 1994 to 2019. It is observed that the number of fires recorded has been increasing over the period. Figure 1 shows an increase over the years with the highest number of fires reached in 2015. This is the year the country suffered from drought. Drought is usually experienced every 3 - 5 years and in periods of sufficient biomass, burning is favored. The years 2008 and 2010 have been classified as two of the warmest on record in the Southern hemisphere compared to a global average. This correlates fairly with fire frequencies. A linear graph drawn shows an increase in the number of fires with a positive slope of 4.868 .

Wildfires in Botswana are usually recorded from August to October. This is the time when there is minimal amount of rainfall recorded in the country so there is drying of biomass from the previous rain season [8]. Also, the low temperatures of the winter season help speed up the drying of the biomass. Figure 2

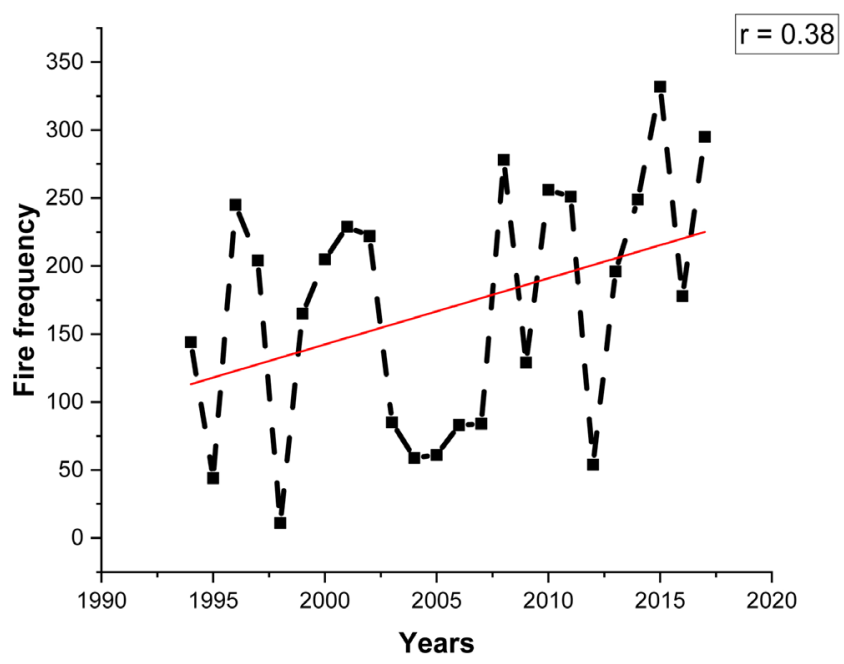

Figure 1. Annual fire frequency for Botswana.

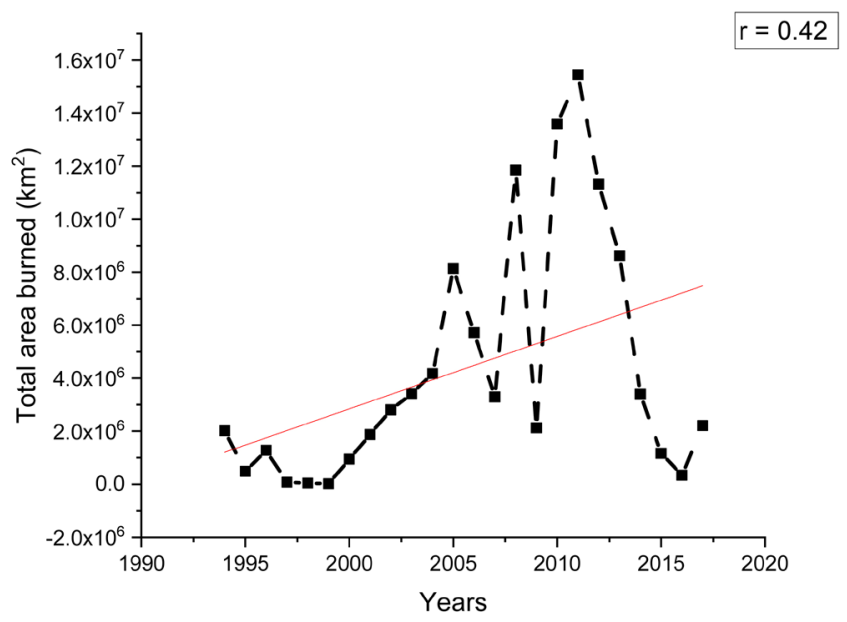

Figure 2. Total area burned for Botswana. 
shows the total area burned over the years from 1994 to 2019. It is seen that the large burn area of $15,000,000 \mathrm{~km}^{2}$ was reported in the country in 2011 . This large area burn was linked to the exceptional high rainfall due to the effect of the la Niña episode and also the build up from previous low burning.

A linear graph shows that the size of area burned in the country continues to grow yearly even though there are some practices (such as the response team) put into place to fight the wildfires.

\subsection{Total Area Burned vs Frequency}

There is no strong correlation between the total area burned and the number of wildfires. The year 2015 shows the highest number of wildfires recorded but only $1,168,362 \mathrm{~km}^{2}$ of land was affected by this. This is because the government has put efforts to curb these wildfires before they cause a devastating damage. This includes using skilled personnel to fight the fires. The districts have been grouped into three (3) zones according to their fire risks. Zone 1 being the most fire prone, includes Ngamiland, Chobe and Ghanzi, has five (5) camps. This is the zone with high burning frequency and large area burned. Other two zones have fewer camps because of the small sizes of the districts and low rainfall. The duties of fire camps include daily patrols, reducing fuel where required and acting as first respondents of fire incidents [5]. Figure 3 shows an exception for the years 2008, 2010 and 2011 where the high number of wildfires led to large area burning.

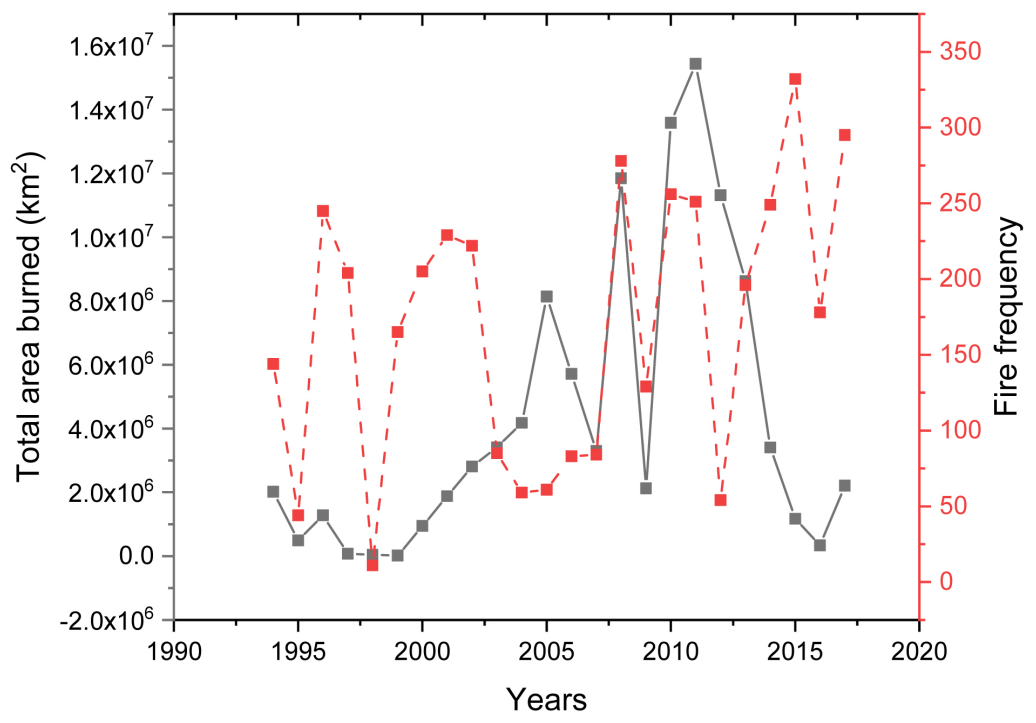

Figure 3. Relationship between total area burned and fire frequency.

\subsection{Wildfires Per District}

Botswana is divided into ten (10) rural districts (Figure 4). In alphabetical order, the districts are Central, Chobe, Ghanzi, Kgalagadi, Kgatleng, Kweneng, North East, Ngamiland, South East and Southern. Central District is the largest by area 


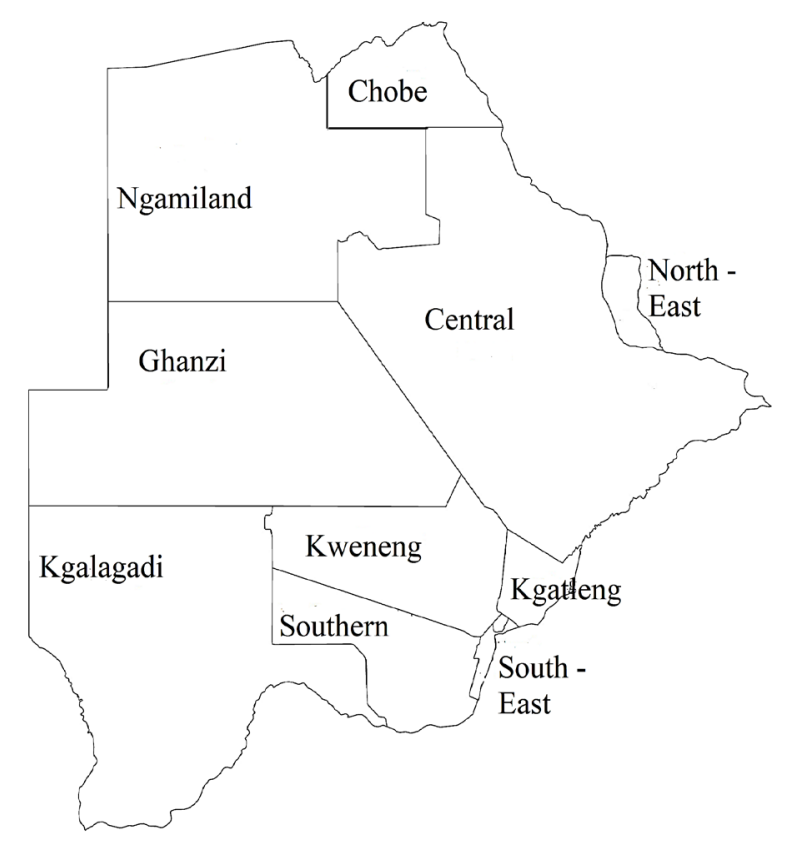

Figure 4. Rural districts in Botswana.

and the most populated one, with an area of 142,076 sq. km. Information of fire detected in each district is recorded and kept by DFRR. The data on area burned for each district available was for the years 2006 to 2017 . Table 1 shows the total number of fires and total area burned for the period of 2006-2017. From this, it is observed that Ghanzi and Ngamiland were mostly affected by the fires with an area of $25,273,530$ and $23,888,153 \mathrm{~km}^{2}$ burning respectively. This is followed by the Central district with area of $9,059,825 \mathrm{~km}^{2}$ burning. The three districts have areas that are well protected by the state such as the largest park in the country the Central Kalahari game reserve. Because of this some fire ignitions take time to be responded to until they grow into large fires. The type of vegetation in these areas is found to be different from the rest of the other districts. Ngamiland district is characterized by Colophosphermum mopane and in the southern part of the country Acacias become more dominant and significantly [9]. Mopane is said to burn slowly and produce a constant heat rate. It therefore takes time for mopane fire to be put out naturally and can take time burning and spread significantly in the presence of unstable weather such as a blowing wind.

Other districts such as Kgatleng, Kweneng and South East with settlements may record several fires but are usually attended to by the marshals before they can grow into mega fires. Kweneng district recorded 264 wildfires in the 11-year period with only $3,930,515 \mathrm{~km}^{2}$ of land burning. This is 79 more wildfires compared to Ngamiland which experienced 6-fold of land burning. Figure 5 shows total area burned and fire frequency for an 11-year period for the 10 rural districts. A peak in area burned is observed across all districts for the years 2008, 2010-2012. These are the years that have been classified the warmest on record in the Southern hemisphere and lead to mega fires in the country. 


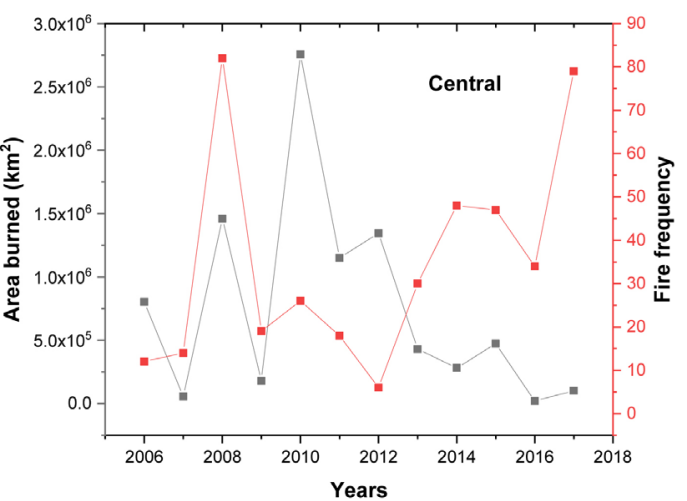

(a)

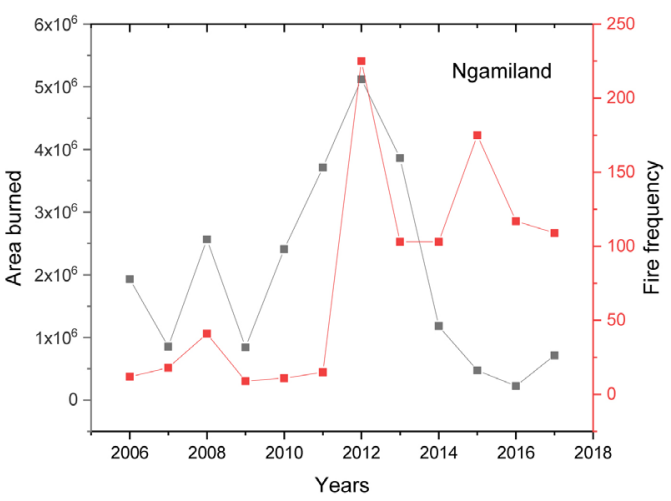

(c)

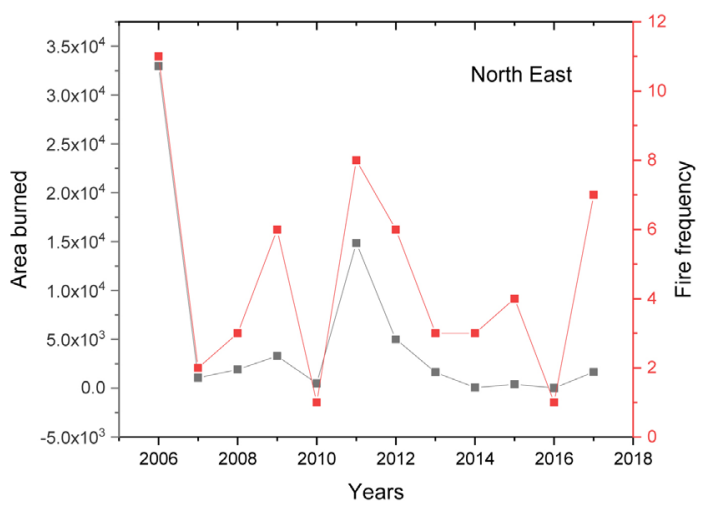

(e)

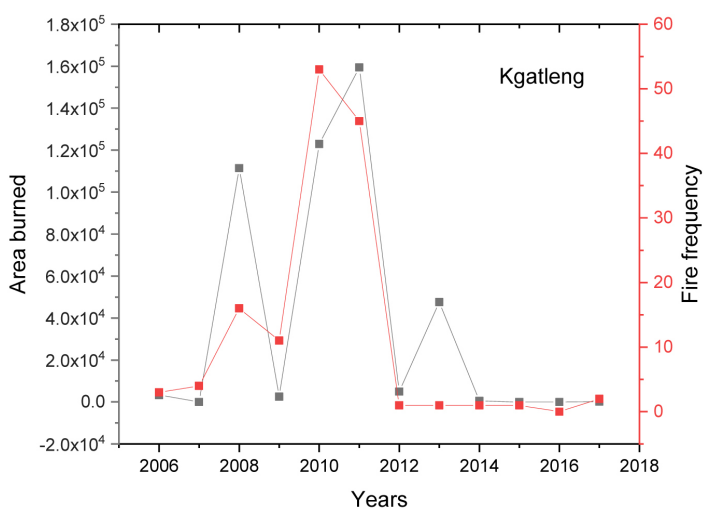

(g)

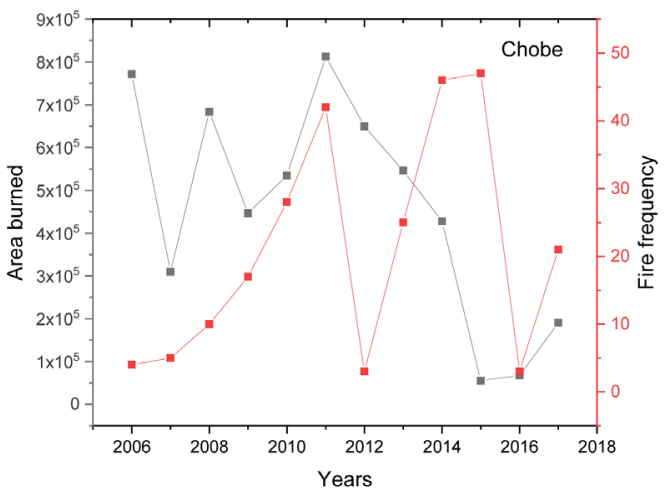

(b)

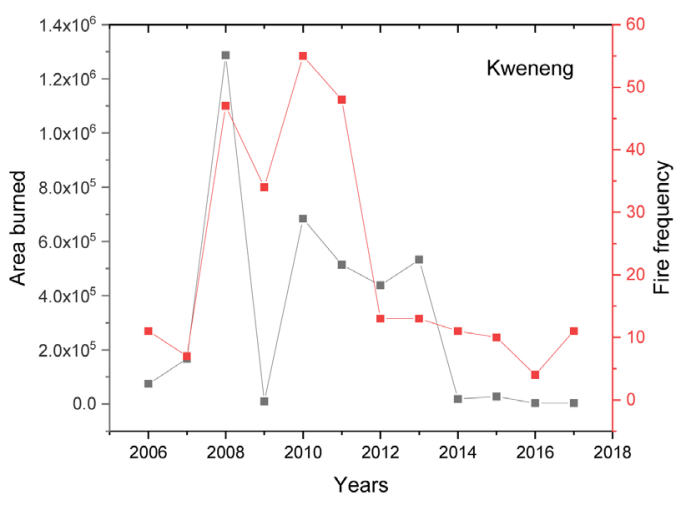

(d)

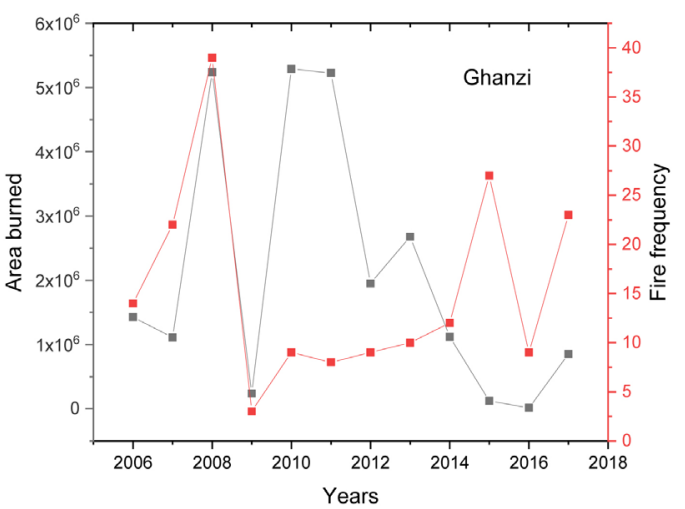

(f)

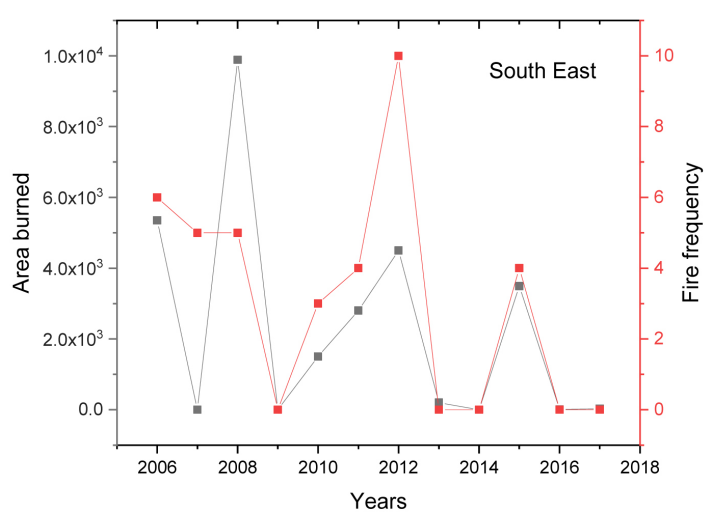

(h) 


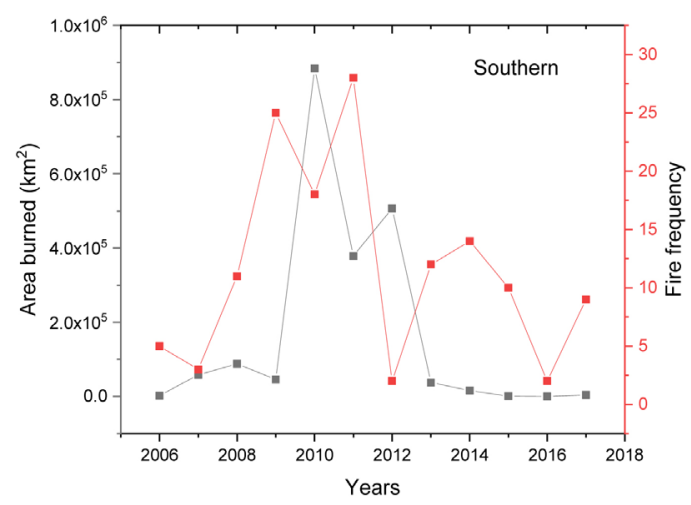

(i)

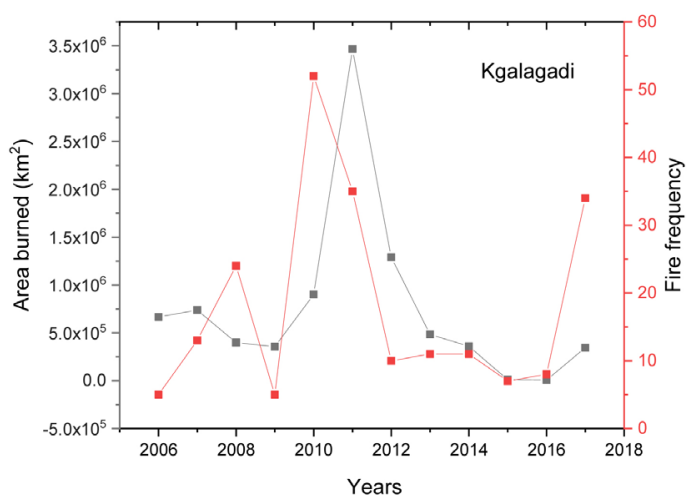

(j)

Figure 5. Total area burned and fire frequency for an 11-year period for the 10 rural districts in Botswana.

Table 1. Total number of fires and total area burned for the period of 2006-2017.

\begin{tabular}{ccc}
\hline District & Number of fires & Total area burned \\
\hline Central & 385 & $9,059,825$ \\
Chobe & 226 & $5,494,877$ \\
Ghanzi & 185 & $25,273,530$ \\
Kgalagadi & 215 & $9,019,276$ \\
Kgatleng & 138 & 452,955 \\
Kweneng & 264 & $3,759,668$ \\
Ngamiland & 938 & $23,888,153$ \\
North east & 55 & 63,339 \\
South East & 37 & 27,774 \\
Southern & 139 & $2,022,842$ \\
\hline
\end{tabular}

\section{Conclusion}

Fires provide an environmental service and are an integral part of the maintenance of the environment, but increased fire activity can lead to adverse effects on the environment. The effects may include disasters such as loss of human and animal life as well as property. There is no strong correlation between the total area burned and the number of wildfires. Some districts have reported many wildfires compared to other ones, but still recorded small areas of land burned. This is due to the efforts put by the government to curb these wildfires before they cause devastating damage such as using skilled personnel to fight the fires. The results shown here show an increase in the number of fires recorded yearly, this will continuously affect the running of operations smoothly.

\section{Acknowledgements}

We thank Ms. Tshegofatso Shadrack from the Department of Forestry and Range Resources for sharing data on areas burned and fire occurrences in Botswana. 


\section{Conflicts of Interest}

The authors declare no conflict of interest regarding the publication of this paper.

\section{References}

[1] Mojeremane, W. (2004) Wildland Fires in Botswana. Fire Management Today, 64, 34-36.

[2] Williams, J., Albright, D., Hoffmann, A.A., Eritsov, A., Moore, P.F., de Morais, J.C.M., Leonard, M., Miguel-Ayanz, J.S., Xanthopoulos, G. and van Lierop, I.P. (2011) Findings and Implications from a Coarse-Scale Global Assessment of Recent Selected Mega-Fires. Proceedings of the 5th International Wildland Fire Conference, Sun City, 9-13 May, 19.

[3] Botswana Environment Statistics: Natural Disasters Digest (2015) Statistics Botswana.

[4] Manatsa, D. and Reason, C. (2017) ENSO-Kalahari Desert Linkage on Southern Africa Summer Surface Air Temperature Variability. International Journal of Climatology, 37, 1728-1745. https://doi.org/10.1002/joc.4806

[5] Dube, O.P. (2014) Challenges of Wildland Fire Management in Botswana: Towards a Community Inclusive Fire Management Approach. Weather and Climate EXtremes, 1, 26-41. https://doi.org/10.1016/j.wace.2013.08.001

[6] Byakatonda, J., Parida, B.P., Moalafhi, B.D., Kenabatho, P.K. and Lesolle, D. (2020) Investigating Relationship between Drought Severity in Botswana and ENSO. Natural Hazards, 100, 255-278. https://doi.org/10.1007/s11069-019-03810-1

[7] Urrutia-Jalabert, R., Gonzalez, M.E., Gonzalez-Reyes, A., Lara, A. and Garreaud, R. (2018) Climate Variability and Forest Fires in Central and South-Central Chile. Ecosphere, 9, e02171. https://doi.org/10.1002/ecs2.2171

[8] Dube, O.P. (2007) Fire Weather and Land Degradation. In: Sivakumar, M.V.K. and Ndiang'ui, N., Eds., Climate and Land Degradation, Springer, 224-251. https://doi.org/10.1007/978-3-540-72438-4 12

[9] Ringrose, S., Matheson, W., Wolski, P. and Huntsman-Mapila, P. (2003) Vegetation Cover Trends along the Botswana Kalahari Transect. Journal of Arid Environment, 54, 297-317. https://doi.org/10.1006/jare.2002.1092 